\title{
Can COVID-19 infection be a trigger for development of rare diseases such as pachydermodactyly?
}

Slavica Janković ${ }^{1 *}$, Jadranka Ban², Zdenka Floršíc ${ }^{3}$, Jakov Babić ${ }^{4}$

${ }^{1}$ Polytechnic "Lavoslav Ružička" in Vukovar

${ }^{2}$ Health center Vukovar

${ }^{3}$ Hospital in Vukovar

${ }^{4}$ Jesuit High School in Osijek

*Corresponding Author: Slavica Jankovi, Polytechnic “Lavoslav Ružička” in Vukovar

Received date: 29 November 2021; Accepted date: 08 December 2021; Published date: 13 December 2021

Citation: Janković S, Ban J, Floršić Z, Babić J (2021) Can COVID-19 infection be a trigger for development of rare diseases such as pachydermodactyly? J Med Case Rep Case Series 2(18): https://doi.org/10.38207/JMCRCS/2021/0218246

Copyright: (C) 2021 Slavica Janković. This is an open-access article distributed under the terms of the Creative Commons Attribution License, which permits unrestricted use, distribution, and reproduction in any medium, provided the original author and source are credited.

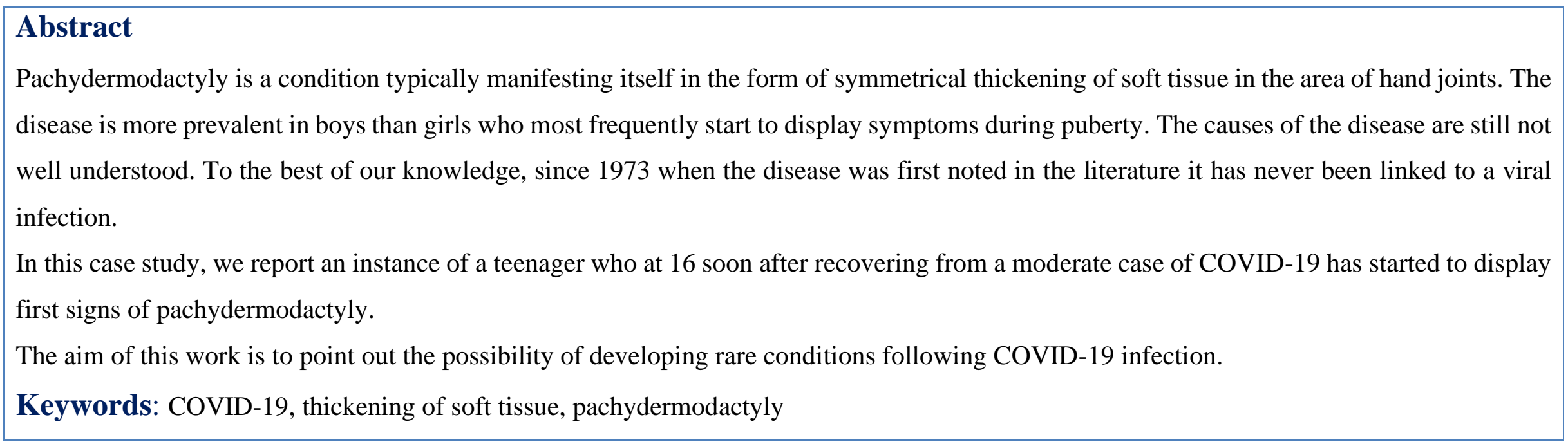

\section{Introduction}

Pachydermodactyly (PDD) is a benign thickening of soft tissue which typically affects symmetrically the area around proximal interphalangeal joints. PDD was first brought up and described by Bazex in 1973 [1]. Since then, only a handful of research works have been published on the topic. That underlines the infrequency of the disease occurrence but also reflects inadequacy in clinical procedures in identifying the diagnosis. According to the available data, only 121 cases ( 25 of those women) have been registered so far in the whole world, including Europe, the US, the Middle East, and Asia. According to the available literature in 2019 there were only four reported cases in a more advanced age group and all four exhibited equivalent clinical symptoms of the disease as for the younger age group.[2]

In the literature, the disease is typically referred to as largely asymptomatic, typically observed in younger males and with only progressive inflammation of periarticular soft tissue [3]. Mechanical trauma, hormonal disbalance, stress conditions, and obsessivecompulsive disorders are considered the most frequent causes of the disease. According to the available descriptive data in only $43 \%$ of the cases the causes are known with the most frequently listed causes being mechanical injuries such as rubbing of hands, injuries provoked by the excessive playing of video games, recurring sports injuries, and/or injuries due to digital manipulation, frequent repercussions from stressful circumstances and high level of excitement [4]. Of the total, 18 subjects with PDD were also diagnosed with Asperger syndrome, which supports the thesis of an existing link between PDD and psychological diseases[5].

First observations of periarticular tissue most frequently occur in boys during puberty. The subjects tend to ask for medical help only after visually observing the condition progression, which is typically three to four years after the first sign of inflammation. Therefore, the usual progression of PDD in young individuals is the disease that occurs early during puberty but gets medically diagnosed only at the beginning of adulthood. The inflammations occur symmetrically in the areas of proximal interphalangeal joints making the symptoms similar to the ones caused by juvenile rheumatoid arthritis [6]. No surprise then that there have been documented cases where patients with PDD were mistakenly given medical treatment for rheumatoid arthritis [7].

The diagnosis for PDD consists of a) a laboratory assessment which in case of PDD should show the negative result for the rheumatoid test (i.e., to disprove the presence of JRA), and b) x-ray diagnostics which confirms inflammatory degenerative changes in periarticular tissue, but without degenerative changes of the corresponding joints, as one more evidence against the presence of JRA[8].

Based on the cases detailed in the published reports, treatment typically consists of 1) local infiltration with corticosteroids, and/or 2) surgical resection in order to maintain the life quality of the subject with PDD. 


\section{Study Case Description}

At the age of 16, a young male subject with no known comorbidities recovered from a moderate case of COVID-19 infection. The symptoms resembled a more serious flu-type condition, but the subject was able to alleviate the symptoms with over-the-counter medications and hasn't required either prescription medicine or hospitalization. Within two months following the infection the subject saw a specialist due to the observable inflammations in the area of the PIP joints of the 2nd, 3rd, and 4th finger as well as symmetrical inflammations in the area of another metacarpophalangeal joint Following the visit to a pediatric rheumatoid specialist, a complete diagnostic exam was done in order to determine if the condition was associated with juvenile rheumatoid arthritis. The exam contained a detailed blood work, including a test for the presence of rheumatoid factors, a rheumatological exam, an X-ray of the subject's hands, desiontmery of the hip, spine, and hand joint, a dermatological exam, ultrasound imaging of the hand joints, and the fingers and ultrasound imaging of the connective tissue, an exam and lab work for metabolic disorders, ultrasound of subject's heart and cardiovascular system as well as a biopsy of the 4th finger which was followed by histopathology of the sample.
A clinical examination indicated inflammations in the area of the PIP and MCP joints, limited range of motion (both bending and extension) of the $3 \mathrm{rd}$ and the 4 th finger as well as pain when trying to perform the motions. The boy denied the existence of morning stiffness. The symptoms/conditions exhibited during the normal daily routine he tried to explain away with certain activities such as long writing assignments in school or other activities that required prolonged closed fist position

An examination of other joints found neither evidence of inflammation nor a limited range of motion. According to the obtained lab results, it was determined that the condition is not juvenile rheumatoid arthritis. Ultrasound and $\mathrm{x}$-ray imaging of the joints found no pathological changes that would indicate a possible rheumatoid disease while the radiological ultrasound determined the existence of inflammations of the connective tissue in the vicinity of the PIP joints as well as accumulation of collagen, though to a smaller degree. Finally, pathohistological analysis of tissue biopsy gave a diagnosis of pachydermodactyly.

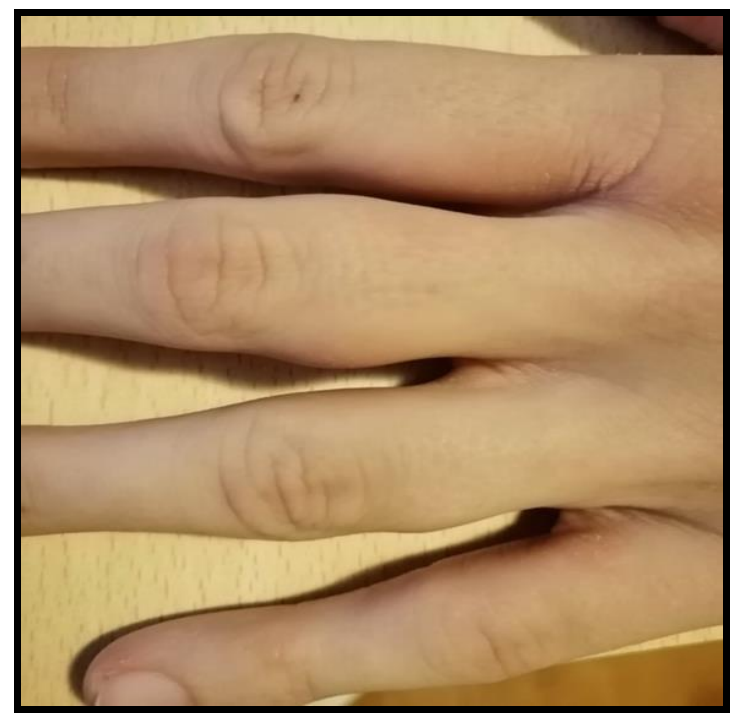

Picture 1: April 2021. (before the hospital visit)

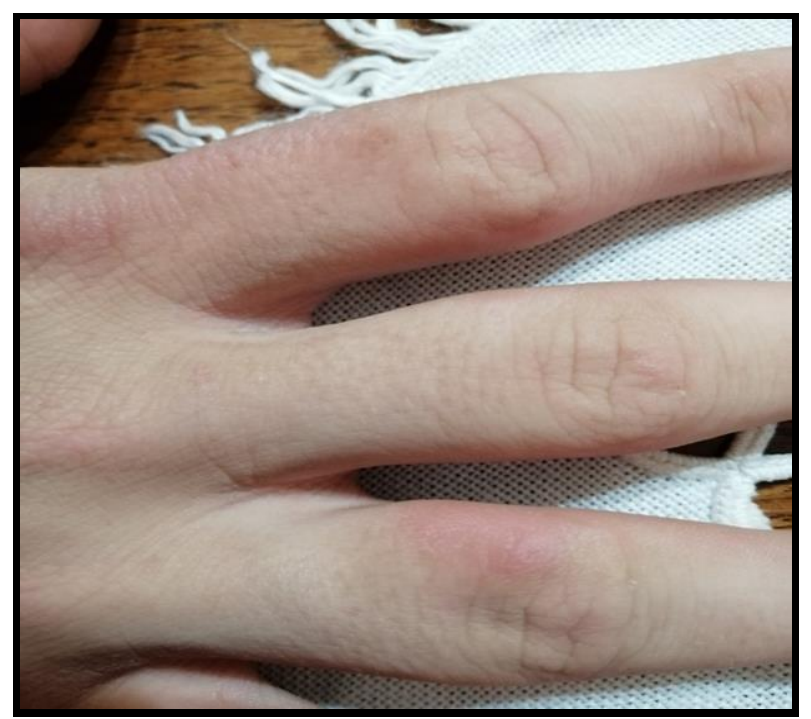

Picture 2: April 2021. (before the hospital visit) 


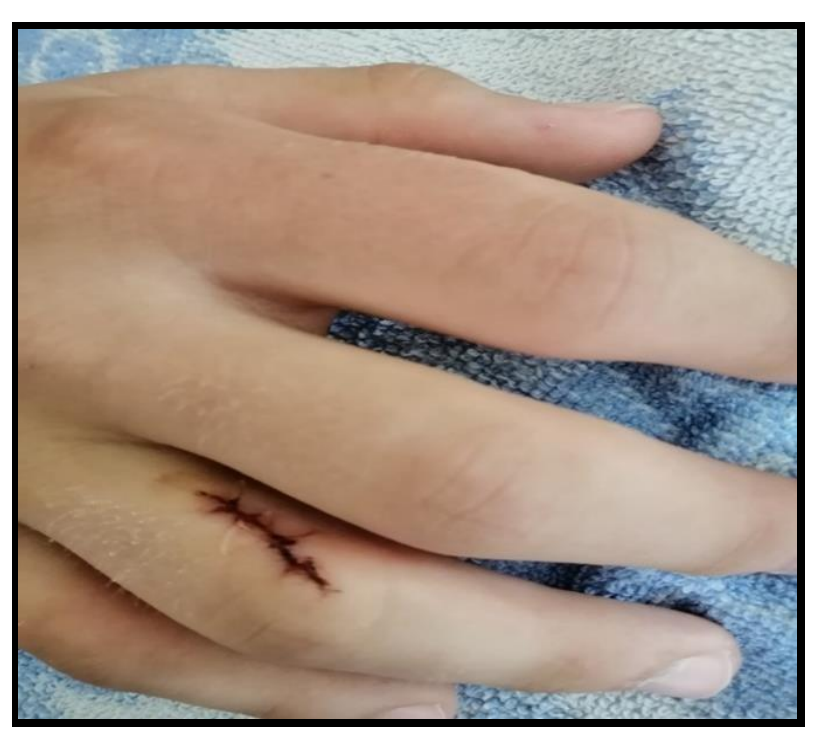

Picture 3: May 2021., (after biopsy)

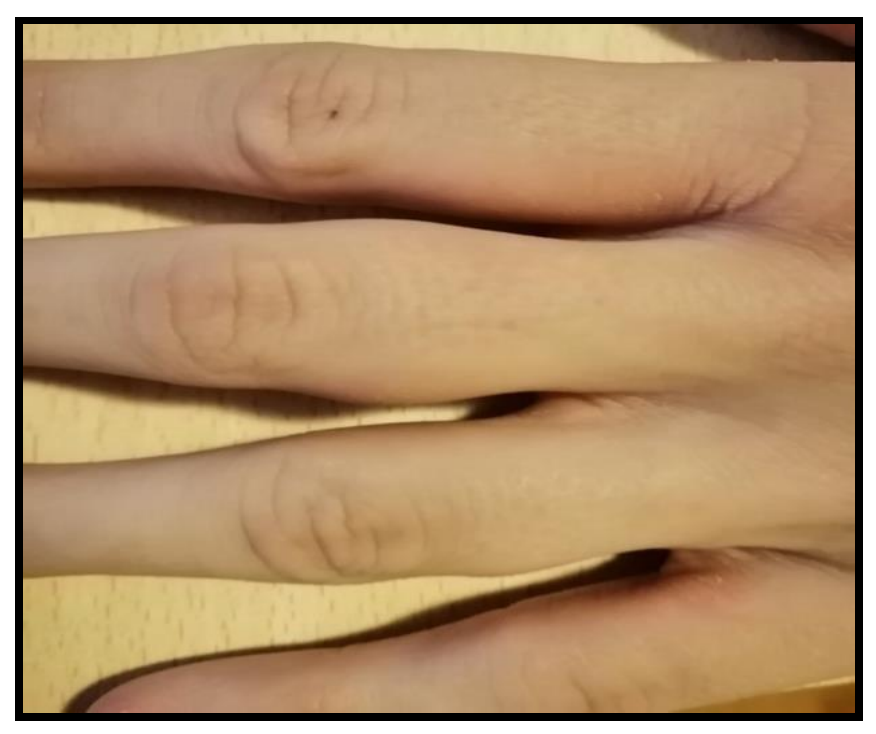

Picture 4: May 2021., (left hand)

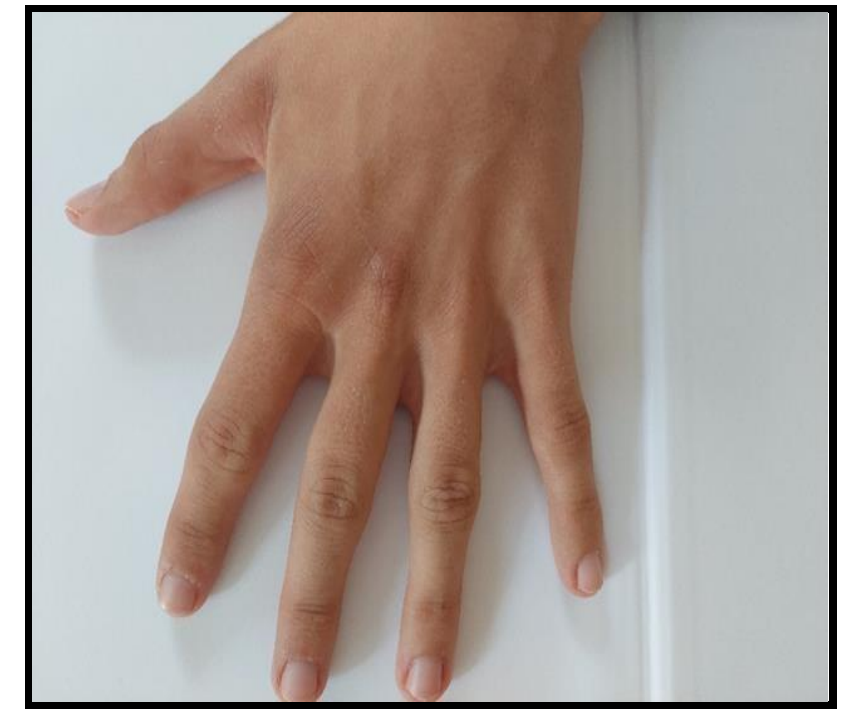

Picture 5: September 2021. (the first day of school - left hand)

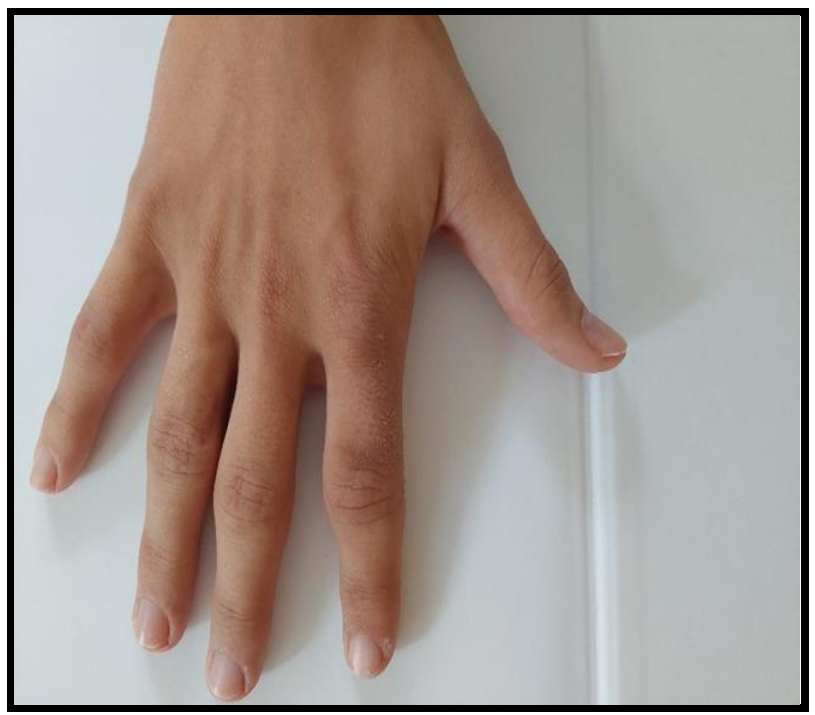

Picture 5: September 2021. (the first day of school - right hand) 


\section{Treatment}

At the two-month follow-up check-up following the earlier diagnostic hospital stay no treatment was prescribed. Rather, since no new

\section{Discussion and conclusion}

Pachydermodactyly (PDD) is a benign thickening of soft tissue. The condition is relatively poorly understood due to very low occurrence and consequently due to the very low number of cases diagnosed. Literature search shows that based on the discussed cases the condition tends to get diagnosed around similar (teenage) age [9] Furthermore, the past research shows that the condition is more prevalent in boys, that the causes and predisposition factors are still very much unclear, and that various treatment suggested and tried typically brings only a limited easing of the symptoms but never a complete remission.

In the case of the young man whose condition is described in this study it was noted that eliminating the school activities that had a detrimental effect on the condition (e.g., writing) the inflammation

\section{References}

1. Basex A, Dupre A, Teillard J. Pachydermie digitale des premieres phalanges par hyperplasie conjonctive dermique et aplasie hypodermique. Bull Soc Fr Dermatol Syphiligr. $1973 ; 80: 455-456$.

2. Nikhila PK, Santhosh P, Jensy NK, Sahadevan NV (2019) Pachydermodactyly: A case report. Journal of Skin and Sexuall. 1(2): 107-109.

3. Sinha NK, Ling SP, Nema SK, Pai DR (2013) Pachydermodactyly does not need rheumatologic work-up. J Postgrad Med. 59(4): 335-336.

4. Bardazzi F, Neri I, Raone B, Patrizi A (1998) Pachydermodactyly: seven new cases. Ann Dermatol Venereol. 125(4): 247-250.

5. Beltraminelli H, Itin P (2009) Pachydermodactyly - just a sign inflammations were observed it was determined that the right course of action is to wait and see, i.e. to monitor the condition progression.

decreased but remained, and the skin redness in the area and pain due to motion subsided. It is to expect that the condition would deteriorate as the detrimental activities resume and reach the usual level of intensity.

Considering that the inflammation of the connective tissue appeared immediately following the COVID-19 recovery the question remains if the COVID infection was indeed a trigger mechanism for initiating the PDD. Such type of a trigger mechanism has never been observed before. On the other hand, there have been reports of Covid-19 triggering a number of other rare conditions in the domain of neurology and rheumatology. With the side effects of Covid largely unknown, one can only assume that the area will remain a subject of numerous research studies.

of emotional distress. Eur J Dermatol. 19(1): 5-13.

6. Wei L, Dong-Lai M (2020) Pachydermodactyly. Mayo Clinic Proceedings. 95(10): 2280-2281.

7. Mesa-Del-Castillo Bermejo P, Martínez Menchón T, de la Peña Moral J, Del Carmen Díaz Faura M (2016) Classic pachydermodactyly. A simulator of juvenile idiopathic arthritis. An Pediatr (Barc). 85(5): 275-276.

8. Nicolay JP, Faulhaber J, Kutzner H, Schneider SW (2015) A new subtype of pachydermodactyly: unilateral pachydermodactyly transgrediens. Clin Exp Dermatol. 40(6): 633-635.

9. Hunt R, Mandal R, Walters R, Schaffer JV (2010) Pachydermodactyly. Dermatol Online J. 16(11): 5. 